\title{
BRASIL-DURBAN-BRASIL: UM MARCO DA LUTA CONTRA O RACISMO
}

\author{
NILMA BENTES \\ Centro de Estudos e Defesa do Negro do Pará/CEDENPA
}

Meu grito de revolta ecoou pelos vales mais longínquos da Terra, atravessou os mares e os oceanos, transpôs os Himalaias de todo o Mundo, não respeitou fronteiras e fez vibrar meu peito...

\section{O magnetismo de uma África ancestral}

Quando se está diante de um mapa do mundo, dos produzidos em nosso país, é quase inevitável pousar imediatamente o olhar sobre a África, o Brasil e o Atlântico. Isso sempre carrega meu pensar para a tragédia da escravidão, e, ato contínuo, meu olhar caminha para a Europa, aquele pedacinho de terra - que alguém já disse ser apenas uma península da Ásia - de onde emanava e emana, ainda, a opressão a milhares de povos no mundo.

Pensar África do Sul é fazer associação quase imediata ao apartheid, Nelson Mandela, Winnie Mandela, Steve Biko, Zulus, Shosds, Congresso Nacional Africano (CNA) e a toda a luta dos africanos daquele país, pelo direito de exercer a liberdade em seu próprio chão.

Detendo o olhar no Brasil, é forçoso pensă nas nações indígenas que, como muitos povos negros na África, até hoje lutam, náo só parar existir, como para ter um lugar em seu próprio território. Pensar nosso país é pensar também no seu tamanho físico e no tamanho das desigualdades sociais nele existentes, onde nós, negros, somos, numérica e psicologicamente, os mais prejudicados entre todos os segmentos que formam sua população.

Apesar disso, felizmente, muitos de nós herdamos da ancestralidade africana, entre outros bens valiosos, o gostar da simples oportunidade de se sentir no mundo, de ter 0 privilégio de se saber parte dessa natureza tão diversificada, tão linda. Essa herança afrocultural faz com que, na maioria de nós, as adversidades da vida não sejam motivo para que desapareça a alegria de estar no mundo. A propósito, percebe-se que esse traço afro, que se tornou determinante no viver da maior parte da população brasileira,

\footnotetext{
Copyright () 2002 by Revista Estudos Feministas

'Trecho da poesia "Meu Grito de Revolta", de Amílcar Cabral, poeta e grande líder político de Cabo Verde, Guiné Bissau. $2^{\circ}$ grau - O Novo Telecurso: Língua e Literatura (Fundação Roberto Marinho). São Paulo: Globo, 1988.
} 
causa um certo 'incômodo' a muitos de nossos opressores, sobretudo, nos mais pasmaceiros cultuadores do eurocentrismo em nosso país.

Entremeando, assim, registros de fatos e divagações, tentarei deixar algumas impressões sobre a III Conferência Mundial contra Racismo, Discriminação Racial, Xenofobia e Intolerâncias Correlatas, ressaltando, desde logo, que se trata de um depoimento, em pretuguês e sob uma ótica particular. Contudo, tentarei não fragmentar demais o ser e a razão de ser ativista do movimento negro brasileiro, há mais de duas décadas, com todos os erros e acertos desse ativismo.

Começo, então, registrando que ir a Durban parecia mais um sonho que uma possibilidade real. Porém, paulatinamente, desde o início do ano 2000, o que parecia tão distante foi ficando cada vez mais perto. Por isso não consigo pensar A Conferência sem me lembrar de muitos trechos do caminho, inclusive dos obstáculos que fomos removendo dia após dia, fazendo com que o 'Atlanticão' fosse ficando cada dia mais estreito, até que a pangéia ${ }^{2}$ se tornasse novamente realidade.

Durban, segundo uma jornalista brasileira lá residente, corresponderia, no Brasil, à cidade de Fortaleza (CE). Mas pode-se dizer também que corresponde a qualquer cidade brasileira, do ponto de vista sócio-racial. Ou seja, os brancos são 'os proprietários' e os negros 'os mais espoliados'. Assim, embora o processo da ascensão dos negros ao poder esteja em curso, ainda falta muito tempo e muita luta para que o apartheid (agora oficioso) seja, de fato, eliminado na África do Sul - em Durban, por exemplo, ainda observa-se que a maioria dos negros reside em neo-bantustões. ${ }^{3}$ De qualquer maneira, o exemplo de lá pode sinalizar para nós, negros brasileiros, que o apartheid informal do Brasil poderá também ser eliminado, mesmo que palmo a palmo.

\section{A biruta mostrava vento favorável}

Permitindo-me fazer uma comparação esdrúxula, penso que, pelos seus efeitos concretos, as Conferências Mundiais da ONU se assemelham às estatísticas brasileiras: são precárias, mas é melhor tê-las como referência do que não dispor de referência alguma. No caso da de Durban, diferentemente de muitas outras conferências que tiveram temas bem definidos - ecologia, mulher e outros -, o campo temático era de largo espectro. Mesmo assim, logo que começou a divulgação oficial, ficamos meio assanhadas(os) com a possibilidade de que o racismo, propriamente dito, acabasse sendo o tema privilegiado.

O tempo foi passando e as informações que surgiam sinalizavam o contrário, ou seja, dificilmente a Conferência seria centrada no racismo. Mas, assim mesmo, persistia uma certa expectativa de que esta era a nossa vez. Nas iniciativas internacionais de combate ao racismo (inclusive nas Conferências de 1978 e 1983), os negros norteamericanos e os sul-africanos tinham conseguido ganhos significativos. Então, em tese, agora seria a vez de o apartheid brasileiro entrar na ordem do dia, já que, como é sabido, o Brasil tem a segunda maior população negra do mundo.

Entretanto, a desistência do governo brasileiro em sediar a conferência preparatória regional da América Latina acendeu um sinal de alerta para o movimento negro. Essa decisão, além de reduzir drasticamente as possibilidades de que milhares de negros brasileiros pudessem participar dessa conferência preparatória, sinalizava também que o Governo Federal não estava disposto a dar o tratamento que o tamanho e a complexidade da questão exigem.

\footnotetext{
${ }^{2}$ Certa teoria afirmando que em época remota todos os continentes eram unidos.

${ }^{3}$ Povoados onde se concentrava a mão-de-obra negra na época do apartheid (oficial).
} 
Paralelamente a isso, mesmo não acreditando muito na possibilidade de participar da Conferência, o Cedenpa procurou seguir os trâmites burocráticos que poderiam nos levar até lá. Assim, muitas instruções foram coletadas diretamente através de sites e outras foram chegando pelo correio eletrônico, de forma que acabamos reunindo muitas informações sobre como participar e coletando um volume significativo de material de excelente conteúdo sobre os temas a serem tratados.

Garantir a presença de nossa entidade em pelo menos uma das reuniões preparatórias era absolutamente necessário para se poder chegar ao grande evento. Nesse particular, nossa inclusão na Articulação de ONGs de Mulheres Negras Rumo à III Conferência foi decisiva pois, a partir disso, os caminhos foram se tornando menos pedregosos. De qualquer maneira, foram meses e meses de trabalho árduo, quando se ficava cuidando dos planos operacionais da Entidade e, ao mesmo tempo, tentando não perder o bonde da história - um olho no padre outro na missa.

Um segundo sinal de alerta foi quando se teve notícia de que a questão dos palestinos e israelenses iria fazer parte das discussões da Conferência. Em nosso entender, se isso acontecesse, certamente iria distorcer o 'espírito' da Conferência, pois, apesar de reconhecermos algumas das facetas xenofóbicas nessa 'questão bíblica', ela não deveria ser incluída na Conferência, já que se liga muito mais a ocupações de territórios e ao imperialismo em si. Ou seja, não se liga diretamente à questão do racismo, da xenofobia explícita, do machismo, da homofobia, da questão dos portadores de necessidades especiais e das outras discriminações que atormentam o cotidiano de muito mais gente que as populações palestina e judia, somadas, residentes naquela parte do Oriente Médio.

Ainda assim, continuamos nutrindo a esperança de que os arranjos e as combinações políticas se dessem de tal maneira que todas as temáticas acabassem sendo discutidas em um clima de razoável entendimento.

\section{Um pouco mais sobre a preparação}

Estava ciente de que quem tivesse conhecimento de outras línguas, sobretudo o inglês, as entidades mais bem organizadas e com experiência em conferências mundiais, teriam, certamente, maiores possibilidades de garantir a participação, inclusive com certa antecedência. Não teriam, por exemplo, que esperar o apagar das luzes para saber se viajariam ou não para Durban.

Acho importante dizer que, no conjunto das organizações negras do Brasil, entendemos que o Cedenpa não se insere nem na vanguarda nem na retaguarda do movimento. Isso porque não acreditamos que um 'trauma social' tão forte quanto o racismo histórico no Brasil possa ser solucionado em um passe de mágica, como também não acreditamos que a classe média negra, embora importante no combate ao racismo, possa, de fato, ser o grande motor de uma transformação social absolutamente inclusiva para o segmento negro. O medo da pobreza e da miséria é praticamente instintivo na classe média, então ela só irá até onde os excessos de 'gorduras' e um pouquinho de sua 'carne' permitirem que ela continue aliada ao povo empobrecido.

Voltando ao processo preparatório, a participação de nossa Entidade se deu principalmente em três eixos: através da Articulação de ONGs de Mulheres Negras Rumo à III Conferência; das reuniões preparatórias do Ministério da Justiça; e através do Fórum de Entidades Negras, participando, nesse caso, como membro da Coordenação Nacional de Entidades Negras (Conen).

Vários documentos consubstanciados que circularam pelo correio eletrônico foram importantíssimos para o entendimento do conteúdo e do nível das discussões que iriam ocorrer na Conferência, e também para forçar-nos a refletir e nos posicionar sobre novos 
e antigos conceitos ligados ao racismo, suas causas, conseqüências e medidas eficazes para neutralizá-los.

Desse processo preparatório saíram os principais pontos que queríamos ver defendidos pelo governo na Conferência. Tais pontos foram:

1. condenação do tráfico de escravos como crime de lesa-humanidade;

2. adoção do princípio de reparações aos povos africanos e afrodescendentes;

3. reconhecimento das bases econômicas de operação do racismo;

4. adoção de políticas públicas corretivas pelos Estados nacionais nas áreas de saúde, educação, habitação e emprego;

5. adoção de políticas de desenvolvimento nas comunidades e terras de afrodescendentes, incluindo acesso às novas tecnologias;

6. adoção de políticas específicas para mulheres africanas e afrodescendenetes;

7. adoção de mecanismos de combate às conseqüências do racismo e da pobreza; corretivas;

8. reconhecimento da prática de racismo no sistema penal e adoção de medidas

9. reforma do sistema legal nacional e apoio à adoção de medidas internacionais que permitam o combate eficaz do racismo;

10. reconhecimento da múltipla discriminação agravada pela orientação sexual;

11. racismo ambiental.

Não obstante esse consenso no plano não-governamental, as notícias que chegavam sobre as reuniões preparatórias no âmbito oficial já começavam a dar mostras das dificuldades que surgiriam na própria Conferência. A realização de uma reunião adicional, em Genebra, não conseguiu limar as principais arestas da bela escultura que todos queríamos que fosse produzida, a qual deveria chegar a Durban com possibilidade de ser exposta, admirada e aprovada por aclamação. Porém, a 'escultura' não ficou pronta

\section{Sobre o Fórum das ONGs}

Além de chegar a Durban com o Fórum Mundial de ONGs já em andamento, o processo de credenciamento para a Conferência praticamente impossibilitou nossa participação efetiva nesse importante evento. Acredito que foi uma perda terrível, pois minha expectativa era enorme em ouvir e ver os grandes expoentes do atual pensamento alternativo. Felizmente nem tudo foi perdido. Consegui ver e ouvir parte da palestra de Rigoleta Menchu, ver e ouvir o pronunciamento de Fidel Castro e assistir a parte de uma mesa que contou com a participação de Winnie Mandela e Angela Davis. Sobre esses eventos, quero destacar que tentei, sem sucesso, através de alguns jornalistas, saber que medidas oficiais o governo Fidel Castro estava adotando para combater o racismo antinegro em Cuba. Evidentemente que esse era um assunto incomodativo que muitos - até de nossas searas - não queriam enfocar.

Na 'mesa das mulheres', Winnie Mandela me pareceu muito 'asséptica', sem aquela aura que cada militante do movimento negro, sobretudo nós, mulheres negras, construiu em torno dela. Já o oposto ocorreu no caso da Angela Davis. Que figura!!! Ela, por si só, já transmitia uma enorme energia de luta; talvez até por ter consciência de sua importância por ser um dos principais ícones da luta de milhares de famílias negras, sobretudo mulheres negras, escravizadas por séculos em todas as Américas.

Cabe destacar, por outro lado, que a ausência de Nelson Mandela, tanto no Fórum de ONGs quanto na Conferência, causou uma enorme frustração em todos que foram na expectativa de ouvir algum pronunciamento desse grandioso líder de todas as lutas contra as opressões sócio-raciais. 


\section{A Conferência}

Acho bom iniciar pelo credenciamento. Foi uma catástrofe organizativa. Praticamente toda a documentação que enviamos para Genebra não teve validade. Provavelmente só as organizações que conseguiram participar de todas as pré-conferências não tiveram grandes problemas. Nós, como todos os outros simples mortais, tivemos que enfrentar as longas filas, diariamente, para conseguir credencial e entrar nos espaços onde estavam sendo discutidos os documentos principais - a Declaração Final e o Plano de Ação.

Por intermédio de algumas fontes, soube que houve uma série de boicotes desde os primórdios organizativos dessa Conferência, inclusive para desqualificar as organizações encarregadas dessa tarefa. Não é muito difícil acreditar nisso, sabendo-se que, se em nível micro esses boicotes acontecem com freqüência, imaginem no campo macro do racismo internacional. Observou-se, então, que, apesar do esquema de transporte ter funcionado bem, surgiram muitos problemas com relação à hospedagem e vários obstáculos foram criados dificultando o acesso pleno aos espaços da Conferência.

Um aspecto não menos difícil de contornar foi a ditadura da língua inglesa. Quase todas as discussões, publicações, informes, estavam em inglês - relativamente poucos em francês, pouquíssimos em espanhol e nada em português. Sabíamos que a língua inglesa seria preponderante, mas foi um exagero!

Por outro lado, um dos grandes problemas que surgiram logo no início da Conferência foi a divulgação de que o Alto Comissariado de Direitos Humanos da ONU não iria aceitar, entre os documentos oficiais, o relatório do Fórum das ONGs, o que, segundo fui informada, era praxe em outras conferências. Outro dos grandes problemas surgidos logo no início foi quando os representantes dos United States of America (USA), juntamente com os de Israel, decidiram se retirar da Conferência. Realmente foi um deus-nos-acuda!

Para o movimento negro latino-americano, foi uma noite insone. Algumas lideranças exponenciais eram pressionadas a fazer análise da conjuntura à luz de informações fidedignas ou não. Levando-se em conta que as organizações brasileiras têm tradição de não saber fazer análise de conjuntura (o Brasil é 'melhor' em análise retrospectiva para constatar os erros das análises de conjunturas), em tese, as organizações negras também sofrem dessa mesma anemia política. Então, as opiniões eram volumosas e divergentes: a União Européia seguiria a decisão norte-americana; os países que tinham débitos com os Estados Unidos seriam forçados a também deixar a Conferência, e o Brasil era um deles; a União Européia não deixaria a Conferência em respeito ao esforço da África do Sul, e por aí seguiam as derivações. Aparentemente, a poeira baixou e nenhum outro país abandonou a Conferência. Para alguns, a saída dos Estados Unidos já estava se tornando uma regra, pois já tinham saído de outras Conferências e/ou não assinado alguns tratados internacionais. Tudo já estava planejado.

\section{Ossos difíceis de roer}

Embora com acesso limitado, pudemos assistir a parte das discussões do texto final do Plano de Ação e, de fato, não só era um processo hipercansativo, como também havia questões que, já se sabia, não chegariam a alcançar o consenso. Aliás, na minha opinião, todas as decisões coletivas deveriam seguir esse processo - de buscar o consenso - pois, mesmo com algumas desvantagens, é muito mais interessante que o da disputa voto a voto, até porque as múltiplas argumentações enriquecem o conteúdo da temática discutida e acaba deixando explícitos quais os atores estão ou não emperrando a tomada de decisão. 
Das sessões que presenciei, quero destacar as seguintes observações:

1. conforme já havia sido notado nas discussões preparatórias, Portugal e Espanha, países mais diretamente implicados nos históricos crimes cometidos na América Latina, simplesmente continuaram se fingindo de mortos. Ou seja, trataram de utilizar o representante da União Européia, que era da Bélgica, como testa-de-ferro de suas posições contrárias à aprovação das reparações aos povos africanos e afrodescendentes. ${ }^{4}$ Evidentemente que os outros principais delinqüentes do processo escravista - Inglaterra, Holanda e França - tinham também na Bélgica seu ventríloquo oficial, para barrar tudo que implicasse dispêndio de recursos financeiros. Logo, a palavra 'reparações' começou a soar como blasfêmia.

2. os Estados Unidos abandonaram a Conferência, mas o Canadá, geminado que é aos mesmos, não só territorialmente mas nos interesses imperialistas, passou a substituí-los e a fazer dobradinha com a União Européia, colocando-se, evidentemente, contrário a tudo que pudesse vir a provocar qualquer redução de 'lucro' - palavra de conteúdo mais sagrado e que pode servir de símbolo do G-7 (ou G-8?);

3. por sua vez, a representante do Paquistão, uma das mais ativas no plenário (e uma das vozes mais 'palestinas'), apesar de ser forte aliada nossa, nas cobranças reparatórias ao mundo enriquecido à custa da exploração histórica, se posicionava absolutamente homofóbica e também fazia ouvido de mercador às reivindicações ligadas à melhoria das relações de gênero;

4. o Brasil, por sua vez, nem parecia o Brasil que conhecemos aqui no Brasil. Com posições altamente progressistas que até admitiam avanços nas ações afirmativas, também foi o grande porta-voz das organizações que defendiam o pleno direito dos homossexuais a um 'viver convencional'. A diplomacia brasileira parecia tão politicamente correta que, como muitos, fiquei acreditando que o Brasil do ltamarati não é o mesmo do Ministério da Educação, ou o da Fazenda ou mesmo o da Presidência da República.

Esse louvável posicionamento oficial do governo brasileiro constatado em Durban já vinha sendo explicitado nas pré-conferências, mas estávamos meio céticos. Então, diante das dificuldades de consenso em alguns pontos, sobretudo do Plano de Ação, sabíamos, já àquela altura, que todo um trabalho teria que ser feito na volta ao Brasil, principalmente tomando por base os 11 pontos citados anteriormente.

Outro aspecto que deve ser destacado é que correram soltas as articulações de todos os matizes, inclusive nas de busca de apoios a projetos sociais junto aos órgãos passíveis de formalização de acordos multilaterais e às agências de cooperação internacional. As entidades que detivessem informações privilegiadas de onde seria essa ou aquela reunião teriam mais chances. Contudo, as disputas por espaços de poder dentro do movimento negro até que não foram tão brabas, já que todas as correntes lá representadas pareciam ter amadurecido durante a preparação. Assim, novos e antigos aliados, novos e antigos adversários trombavam nos corredores dos espaços da Conferência e nos restaurantes do entorno sem que maiores complicações fossem explicitadas. Parece que só alguns poucos se sentiam apenas o máximo! Humanos, demasiadamente humanos! ${ }^{5}$

Cabe dar relevo, por outro lado, ao intenso trabalho, no acompanhamento das discussões oficiais, das delegadas da Articulação de ONGs de Mulheres Negras (Crioula e Geledés, principalmente), de representantes da Articulação de Mulheres Brasileiras (AMB) (Cfemea, sobretudo), do representante da Comunidade B'ahai, do Escritório Zumbi dos

\footnotetext{
${ }^{4}$ Afrodescendentes são os descendentes de africanos negros, escravizados fora da África no processo de construção do capitalismo internacional eurocêntrico. Costumo dizer que se trata de um 'nome científico', pois o termo foi criado para 'suavizar' e/ou 'substituir' o outro termo mais usado - 'negro', tido como pejorativo.

${ }^{5}$ Título de um livro de Friedrich Nietzche. Ecce homo: como alguém se torna o que é. Tradução, notas e posfácio de Paulo César de Souza. São Paulo: Companhia das Letras, 1995.
} 
Palmares e do lbase. No tocante a articulações gerais, deve ser registrado o trabalho da vice-governadora do Rio de Janeiro e de lideranças ligadas à Conen, ao Movimento Negro Unificado e à Central Única dos Trabalhadores. Além disso, não poderia deixar de ser ressaltado que a relatoria geral da Conferência ficou a cargo da doutora Edna Roland, pertencente à organização negra Fala Preta.

O Cedenpa foi uma das três organizações negras brasileiras que falaram nas plenárias abertas a pronunciamentos. ${ }^{6} \mathrm{O}$ sacrifício para conseguir ocupar esse espaço foi imenso; ninguém explicava direito onde era o local das inscrições, e o pronunciamento tinha que ser traduzido para o inglês. Bem, de qualquer forma, valeu a pena, pois todos os representantes negros se saíram muito bem em suas falas e, como já sabíamos, o trabalho maior seria mesmo aqui no Brasil.

Detectou-se que um dos problemas que poderiam dificultar nossas articulações aqui era a ausência de grandes lideranças da política nacional. Isso, àquela altura, só reafirmava nossas constatações sobre o pouco empenho da classe política em relação às causas dos índios e dos negros - poucos se sensibilizam com as discriminações diárias que enfrentamos. Aliás, a exemplo do que alguém já disse a respeito dos democratas e republicanos nos USA, na questão do racismo a diferença entre a esquerda e a direita no Brasil é a mesma da Coca-Cola para a Pepsi-Cola!

\section{A diversidade em todos os cantos}

A Conferência foi um espetáculo impressionante de diversidade humana. Talvez só em uma conferência com essa temática seja possível observar tanta diversidade, pois, embora a representação diplomática seja 'naturalmente' diversificada, os segmentos sociais que participam das conferências podem não ser. No caso do Brasil, por exemplo, nunca houve tanta participação de negros em uma Conferência, até porque o próprio racismo se incumbe de reduzir nossas possibilidades de comparecer a grandes eventos. Mesmo na Eco-92, realizada no Rio de Janeiro, a representatividade negra foi reduzida.

Em Durban, aos homens e às mulheres africanos negros/as e brancos/as, se misturavam homens e mulheres hindus, indígenas, asiáticos, afrodescendentes, eurodescendentes, baixos, altos, gordos e magros. Muitas vezes os trajes e adornos, por si só, já revelavam a procedência ou mesmo o compromisso temático de cada um. A diversidade é fabulosa e a luta para mantê-la deve ser constante. Imagine-se indo hoje a um supermercado convencional e depois se dirigir a outro em que todas as prateleiras estejam absolutamente repletas de copos de iogurte da mesma marca e do mesmo tamanho. Não conheço quem preferiria freqüentar o segundo, mas, quando se fala em respeitar diferenças raciais, culturais e étnicas, tudo fica mais difícil. E este era o objeto-centro da própria Conferência: respeitar a diversidade. Toda essa pluralidade podia ser observada tanto dentro quanto fora do espaço oficial da Conferência - nos restaurantes, nas lojas, nas ruas -, já que Durban foi praticamente invadida pelos milhares de participantes do evento.

\section{Enfim, cerrando o pano}

Seria gravíssimo se não desse relevo aqui à Marcha Mundial Contra o Racismo, organizada pelo Fórum de ONGs. Que coisa magnífica!!! Participar de uma marcha junto a milhares de pessoas vindas de todos os países, seguindo o ritmo vibrante e as 'chamadas' dos zulus, shosas, dos ativistas do CNA e de dezenas de lideranças ali presentes, foi um dos momentos mais emocionantes vividos naqueles dias em Durban.

\footnotetext{
${ }^{6}$ As outras foram o Núcleo de Estudos Negros (NEN) e a União de Negros pela Igualdade (Unegro)
} 
A emoção era tanta que não precisava entender o que diziam. Precisava só repetir as palavras de ordem, mesmo que com pronúncias deformadas; precisava deixar que a vibração não encontrasse resistência em qualquer parte do corpo. Foi assim, traspassada de emoção, que vivi aquelas horas nas ruas de Durban. Parecia que a maioria dos que estavam ali queria mostrar ao mundo a força de sua luta; queria mostrar que quando a causa é justa nenhum obstáculo deixará de ser removido. Foi emocionalmente avassalador! Mesmo reconhecendo que nem todos que ali estavam sentiram aquele momento dessa forma, quase desvairada, confesso que estive em tempo real comigo mesma.

Outro momento emocionante foi o discurso da presidenta da Conferência, Nkosazana Dlamini Zuma, na plenária final. Puxa vida! Como temos pessoas brilhantes no mundo! Dá gosto ouvir um discurso daqueles (procurem-no nos relatórios). Infelizmente o sistema só estimula a divulgação do que lhe é absolutamente conveniente - sobretudo a mídia atrelada. Todos sabemos que a mídia tem como alimentos vitais o escândalo, o exótico, o crime, a exceção enfim. Assim, ela acabou fazendo com que a maioria acreditasse que a Conferência foi inteiramente dominada pela questão árabe-israelense. Meio verdade!

Há muita dúvida, aliás, sobre até que ponto a retirada dos Estados Unidos e de Israel da Conferência de Durban foi ou não a gota d'água para desencadear os acontecimentos de 11 de setembro, em Nova York. Mas não há qualquer dúvida de que só a condenação do tráfico de escravos como crime de lesa-humanidade já foi uma conquista importantíssima. No nosso caso, o processo inteiro que culminou na Conferência proporcionou, acredito, o maior impulso que a luta contra o racismo antinegro no Brasil já teve até agora. Talvez porque, em uma casa onde não existe qualquer utensílio, a obtenção de um simples caneco de lata de Leite Moça faz uma grandíssima diferença. Por isso, no caso da luta contra o racismo brasileiro, ratificando o que dissemos no início, ruim com a ONU, pior sem a ONU.

Nós, do movimento negro de hoje, cientes de que tudo que fizermos ainda será muito pouco diante da magnitude da nossa causa, temos, mais do que nunca, de continuar fazendo cada qual a sua parte, de preferência sem brigas, conscientes de que o trabalho será, no mínimo, triplicado. Para dar conta disso, é de bom alvitre procurar ativar o afro bom humor herdado, sobretudo nos momentos de maior tensão. E, uma vez que na morte teremos toda a eternidade para descansar, então, mãos à obra!

Como podem perceber, Durban me deixou absolutamente otimista - que seja infinito enquanto dure! 